\title{
Geographical Distribution of Hepatitis E Virus Genotypes from Animals in China
}

\author{
LIU Min ${ }^{1,2}$, LI Lijuan ${ }^{1}$, XIAO Wen ${ }^{2}$ \\ ${ }^{1}$ School of Public Health, Dali University, Dali 671000, China; \\ ${ }^{2}$ Institute of Eastern-Himalays Biodiversity Research, Dali University, Dali 671003, China
}

\begin{abstract}
Hepatitis $E$ virus is a pathogen spread through the intestine and belongs to the hepevirus of the hepeviridae. HEV can mainly spread through the dung-the mouth way in the crowd, at the same time can be spread by animals. Research shows that many kinds of animals can be used as a natural reservoir of HEV. Judging from the molecular level, HEV is a non-enveloped single-strand RNA virus. It not only can cause sporadic cases of acute hepatitis $E$, but also can cause large-scale outbreaks. As genetic sequencing technology is more and more mature, $\mathrm{HEV}$ can be at least divided into four genotypes by sequencing its whole gene or partial gene and it has obvious geographical distribution in the crowd. From a global perspective: genotype I is mainly in Asia and Africa. Genotype II is confined Mexico and Africa. Genotype III is widely distributed around the world. Genotype IV is mainly in Asian countries. Due to hepatitis $e$ is a kind of zoonosis, therefore HEV genotype in animals should also have a certain distribution rule. In this paper, I have a review of all the literature on HEV genotypes in China from animals in order to sort out the geographical distribution of HEV genotypes and understand the geographical distribution of HEV genotypes in China about animals.
\end{abstract}

Keywords: Hepatitis E Virus; genotypes; animals; geographical distribution.

\section{Introduction}

Hepatitis $\mathrm{E}$ is a infectious diseases with clinical and epidemiological characteristics of acute viral hepatitis caused by hepatitis $\mathrm{E}$ virus(HEV) which mainly used the intestinal transmission, and it is following the hepatitis A that another kind of transmission through the intestinal viral hepatitis cause serious damage to human health. HE is mainly transmitted by the fecal-oral route[1], including transmission through water and food. The transmission through water causes the outbreak of hepatitis and explosive epidemics mainly, While transmission through food mainly causes sporadic infection. The number of the clinical acute hepatitis caused by HEV is more than half. Our country is one of the most serious countries due to hepatitis $\mathrm{E}$ economic burden of illness and death[30]. In addition, the animal associated with human closely also be found hepatitis $\mathrm{E}$ virus in its body. At the same time detecting HEV genotype in animals and in patients with local people of HEV have the same genotype, so Clayson et al. put forward hepatitis should belong to a kind of zoonosis [2].

\section{Host Animals of HEV}

In the last century, Balayan et al.[3] first reported the results of the study in the former Soviet union that HEV can infected pigs, sheep and mouse. In 1997, Meng et al.[4] first isolated HEV from 15 pig farms in the Midwest of the United States, and found that the HEV had highly homology with people. Then about the study of HEV in animals caught the attention of the scholars and a lot of research.

In the thesis of LIU Kun [5], its host animals of HEV are classified as the following:
1) Primates are the natural reservoir of HEV. Chimpanzees, macaque, African green monkey, marmoset, says the monkey, cynomolgus monkeys, squirrel monkeys and other primates is sensitive to $\mathrm{HEV}$, as an ideal experimental animal in the research of the HEV.

2) Rodents are the natural reservoir of HEV. Researchers in the United States are on a variety of HEV rats and found that there is a natural infection of HEV in rodents.

3 ) Pig is the natural reservoir of HEV. Many studies have shown that pigs are the natural reservoir of $\mathrm{HEV}$, and pigs in different growth time of HEV infection serious situation is different [6].

4)Birds can be also the natural reservoir of HEV. But popular in poultry HEV is different from the isolated from mammals HEV, nucleotide sequence homology is only about $50 \%$ [7]. Some scholars proposed to avian HEV as liver virus with hepatitis $\mathrm{E}$ virus in genera a separate genus of equal status [8].

5)Other animals, such as cattle, sheep, dogs, cats, horses and so on. Research shows that HEV antibodies are found in animal serum. Therefore, the phenomenon of the spread of the HEV with animals should not be ignored.

\section{HEV Genotype and its Geographical Distribution}

At present, although we find that there is only one serotype of $\mathrm{HEV}$, yet from different isolates we can find its nucleotide variation is very big, so the researchers have different opinions on HEV types. However, accepted by most scholars widely HEV is divided into four genotypes, gene I, II, III, IV type. In the worldwide population of these four genotypes have obvious geographical distribution. Genotype I mainly distributed in Asia and Africa. Genotype II limited distribution in Mexico and Africa. Genotype III widely 


\section{International Journal of Science and Research (IJSR) \\ ISSN (Online): 2319-7064}

Index Copernicus Value (2013): 6.14 | Impact Factor (2014): 5.611

distributed around the world. Genotype IV mainly distributed in Asian countries. At the same time, through to the HEV from animal origin gene sequencing and the size of the amino acid homology and phylogenetic tree analysis to determine the parting. Therefore this article summed up the others research animals hepatitis $\mathrm{E}$ genotype distribution characteristics through the literature to provide a reference basis for subsequent researchers.

The following figure (mainly for pigs) in animals, at this stage confirmed only the existence of HEV genotype IV regions are Macao[9], Beijing[10], Gansu[11], Guizhou[12, 13], Guangxi[14], Guangdong[15], Hainan[9], Heilongjiang [16], Hebei[17], Jilin[13, 16], Liaoning[16], Inner
Mongolia[10], Ningxia[13], Qinghai[9], Shaanxi[13], Shanxi[13], Tianjin[13], Hong Kong[9], Xinjiang[10], Yunnan[18, 19]. Confirmed genptype III, IV regions at the same time are Anhui[9, 13, 14, 20], Fujian[9, 13], Hubei[9, 13, 21, 22], Hunan[9, 21], Jiangsu[13, 14], Jiangxi[9, 23], Shandong[9, 24], Shanghai[10, 14, 25, 26], Taiwan[27], Zhejiang[13, 14]. Only confirmed genotype I, III, IV region at the same time is Henan $[9,21,28]$. In three areas of Chongqing, Sichuan and Tibet there are no reports of genotype related literature, thus temporarily to animal HEV genotype is unknown area.

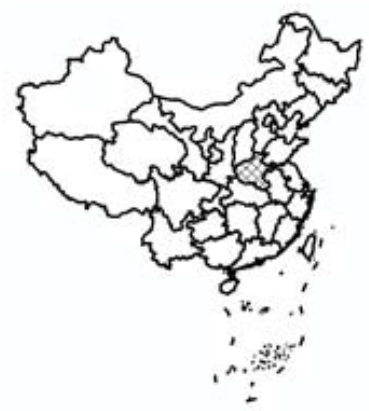

Genotype I

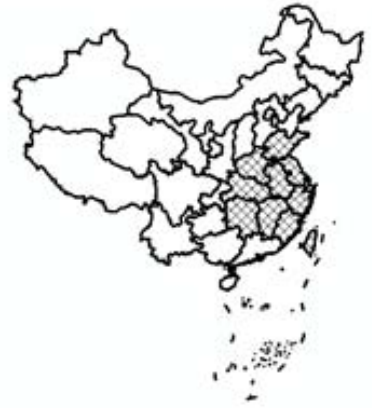

Genotype III

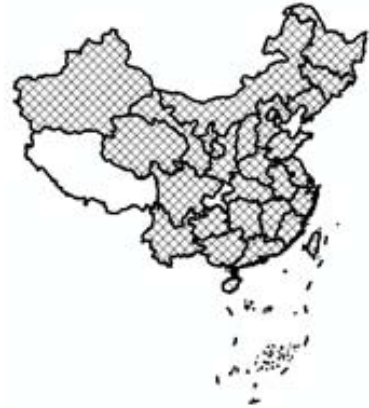

Genotype IV

Figure 1: Animal origin in China the geographical distribution of hepatitis e virus genotypes

\section{Discussion}

Hepatitis E is a global disease which is gradually rising. It is estimated that about one-third of the world's population is infected with HEV[29]. In recent years, China's economic development is getting better and better, the people's standard of living in China is more and more high and we contact more and more frequently around the world, so the public health significance will be more and more attention, $\mathrm{HEV}$ is likely to become one of the important indices for international trade in animal products testing. HEV genotype IV is temporarily not found in Tibet but exists in other areas, and it is the advantage of HEV genotype of animal origin in our country. While in the serum and faeces of patients with hepatitis $E$ in our country we found only HEV genotype I and IV, and genotype IV HEV infection is major [31]. In our country, HEV genotype IV not only dominates in the animals, but also is a advantage genotype in the crowd. At the same time, studies have found that HEV isolated from animals is particularly high homology with HEV isolated from the crowd in our country[32]. It can be used as explanation for hepatitis e is an important cause of zoonosis.

Except in the chicken may cause the obvious big liver and spleen disease clinical manifestations, natural infection of HEV animal is not obvious clinical symptoms. But the pig, chicken, cattle, sheep and so on these animals are the main livestock in our country, is people's main meat consumption. HEV can be a large number of copy stored in these hosts to infect humans, and cause hepatitis E is popular in the crowd, then bring potential threat to human public health. Therefore, the safety problems of animal source spread hepatitis E should arouse people's attention. At the same time, relevant departments should be strengthened for livestock inspections of $\mathrm{HEV}$ infection, thus reducing hepatitis $\mathrm{E}$ transmitted through animals to humans. Eventually weakened the threat to people's health and reduce the economic burden of the social and family because of illness and death caused by $\mathrm{HEV}$, so as to maximize the lower HEV effects on people.

\section{References}

[1] LI Lingjun, ZHU Yonghong, WANG Ling, et al. Progress of research on transmission and pathogenesis of hepatitis $\mathrm{E}$ virus[J]. Chin J Epidemiol, 2009, 30(12):1307-1310.

[2] Clayson E T, Innis B L, Myint K S, et al. Detection of hepatitis $\mathrm{E}$ virus infection among domestic swine in the kathmandu valley of nepal[J]. Am J Med Hyg, 1995, 53(3):228-232.

[3] Balayan M S, AndjaParidze A G, Savinskya S S, et al. Evidence for a virus in non-A, non-B hepatitis transmitted via the fecal-oral route[J]. Intervirology, 1983,20:23-31.

[4] Meng X J, Purcell R H, Halbur P G, et al. A novel virus in swine is closely related to the human hepatitis $\mathrm{E}$ virus [J]. Proc Nstl Acad Sci USA, 1997, 94(1): 9860 - 9865.

[5] LIU Kun. Epidemiological investigation and analyze of zoonotic hepatitis $\mathrm{E}$ virus[D]. Changchun University of Science and Technology 2009 


\section{International Journal of Science and Research (IJSR) \\ ISSN (Online): 2319-7064}

Index Copernicus Value (2013): 6.14 | Impact Factor (2014): 5.611

[6] ZENG Xiaohua, CHEN Tieqiao. The epidemic research of swine $\mathrm{HEV}[\mathrm{J}]$. Progress in Veterinary Medicine, 2006, 27(sup): 26-30.

[7] Peralta B, Biames M, Ordonez G, et al. Evidence of widespread infection of avian hepatitis $\mathrm{E}$ virus(avian $\mathrm{HEV})$ in chickens from Spain[J].Veterinary microbiology, 2009, 137(1-2):31-36.

[8] Meng XJ. Hepatitis E virus: animal reservoirs and zoonotic risk. Veterinary mierobiology, 2010, 140(34):256-265.

[9] Peng Liu, Lingjun Li, Ling Wang, et al. Phylogenetic analysis of 626 hepatitis $\mathrm{E}$ virus(HEV) isolates from humans and animals in China (1986-2011) showing genotype diversity and zoonotic transmission[J]. Infection, Genetics and Evolution,2012,12:428-434.

[10]ZHU Yumin, DONG Shijuan, Yu ruisong, et al. In our country human and swine hepatitis E virus (HEV) genotype and its epidemic situation analysis. The Third National Conference On Zoonoses. 113-118.

[11]FENG Ruofei, MA Zhongren, QIAO Zilin, et al. HEV seroepideiology and genotypes among pigs in Lanzhou city[J]. Chin J Public Health, 2010, 26(6): 715-716.

[12]REN Rongqing, ZHANG Dengxiang, XU Jinge, et al. Molecular epidemiological investigation of swine hepatitis E virus in Guizhou Province[J]. Chinese Veterinary Science, 2011, 41(9): 960-967.

[13] Yansheng Geng, Chuanbin Wang, Chenyan Zhao, et al. Serological prevalence of hepatitis $\mathrm{E}$ virus in domestic animals and diversity of genotype 4 hepatitis $\mathrm{E}$ virus in China $[\mathrm{J}]$ Vector-borne and Zoonotic Diseases, 2010,10:765-770.

[14]XIA Yugang. Molecular and evolutional characteristics of zoonotic hepatitis E virus[D]. Fudan University 2011

[15]ZHANG Liangquan, LIANG Huanbin, WANG Heng, et al. Epidemiological investigation of swine hepatitis $\mathrm{E}[\mathrm{J}]$. China Animal Husbandry \& Veterinary Medicine, 2012, 8: 215-219.

[16] SUN Jinwei. Seroepidemiology and genotype analysis of hepatitis Evirus in the northeast of China[D]. Changchun University of Science and Technology 2009

[17] Yangsheng Geng, Hongxin Zhang, Jun Li, et al. Comparison of hepatitis $\mathrm{E}$ virus genotype from rabbits and pigs in the same geographic area: no evidence of natural cross-species transmission between the two animals[J]. Infection, Genetics and Evolution,2013,13:304-309.

[18] LI Wengui, SHE Ruiping, LI Ruiwen, et al. Investigation of hepatitis E virus infection in the slaughtered swine in Kunming of Yunnan Provine[J]. Chinese Veterinary Science, 2010, 40(03): 636-641.

[19] Wengui Li, Xianghua Shu, Yangliu $\mathrm{Pu}$, et al. Seroprevalence and molecular detection of hepatitis $\mathrm{E}$ virus in Yunnan province, China[J]. Arch Virol,2011,156:1989-1995.

[20]XIA Yugang, HU Anqun, LIU Haiyan, et al. Phylogrnrtic analysis of hepatitis $\mathrm{E}$ virus isolates from both human and swine in Anqing[J]. The Tenth Epidemiological Academic Conference In East China, 204-208.

[21]ZHONG Houyong. The molecularly epidemiological investigation of swine hepatitis $\mathrm{E}$ virus and ORF2 cloning and expression[D]. Huazhong Agricultural University 2009

[22]ZHAO Chenyan, LIU Xiaogui, FAN Jinping, et al. Partial sequence analysis of hepatitis E virus isolated from patients and pigs in Hubei, China[J]. Chin J Viral Dis, 2013, 3(1): 27-31.

[23]ZHANG Xu. Development of a RT-nPCR assay for swine hepatitis $\mathrm{E}$ virus and isolation of the SHE-JX strain [D]. Jiangxi Agricultural University 2011

[24] SONG Tengfei, ZHAOQin, YAO Yonghong, et al. Detection and gene sequence analysis of swine hepatitis E virus Tai'an of Shandong Province[J]. Chinese Journal of Animal Infectious Diseases, 2011, 19(3): 23-27.

[25] Fu-sheng Si, Yu-min Zhu, Shi-juan Dong, et al. Full genomic sequence analysis of swine genotype 3 hepatitis $\mathrm{E}$ virus isolated from Shanghai[J]. Virus Research,2009,144:290-293.

[26] Ning H, Niu Z, Yu R, et al. Indentification of genotype 3 hepatitis $\mathrm{E}$ virus in fecal samples from a pig farm located in a Shanghai suburb[J]. Vet Microbiol,2007,121:125130.

[27] Wu JC, Chen CM, Chiang TY, et al. Spread of hepatitis $\mathrm{E}$ virus among different-aged pigs: two-year survey in Taiwan[J]. J Med Virol. 2002,66(4):488-92.

[28]LI Xiuji. Epidemiological survey on the intection of hepatitis E virus among pigs in partial regions of China [D]. Academy of Military Medical Sciences 2007

[29] Khuroo MS, Khuroo MS. Hepatitis E: an emerging global disease-from discovery towards control and cure [J]. J Viral Hepat. 2015 Sep 6. Doi: 10.1111/jvh. 12445.

[30] Worm HC, Wirnsberger G. Hepatitis E Vaccines: Progress and Prospects[J]. Drugs, 2004, 64(14): 15171531.

[31]FU Hongwei, ZHU Yonghong, ZHUANG Hui. Progress of epidemiological research on hepatitis $\mathrm{E}$ in $\mathrm{China}[\mathrm{J}]$. Chin J Viral Dis, 2011, 1(1): 67-70.

[32]HU Guangdong, MA Xun. Detection and sequences analysis of Bovine hepatitis E virus RNA in Xinjiang Autonomous region[J]. Chinese Journal Of Virology, 2010, 26(1): 27-32. 